\title{
Architecture Design Proposal as a Syntax for Elderly Rejuvenation
}

\author{
Grace Novita Silalahi dan FX. Teddy Badai Samodra \\ Departemen Arsitektur, Fakultas Arsitektur, Desain dan Perencanaan, Institut Teknologi Sepuluh Nopember (ITS) \\ e-mail: fxteddybs@arch.its.ac.id
}

\begin{abstract}
Every year there are an additional number of elderly. Old age is the phase of human life cycle where the elderly feels it as the life phase with the longest journey. In this phase elderly mostly feel lost part of themselves and cause depression because elderly feeling lost part of themselves. The elderly as an independent person doesn't want to depend on their child or their family both physically and economically. Architectural object design for productive elderly that still can fulfil their daily needs and they have desire to work again to spent the rest of their life time for aging productively in a community to work and for life. The proposed architectural object is SOHO (Small Office Home Office) for productive elderly and youth can both learning from each other and working together in one community. Biomimetic from beehive ecosystem level to approach behavior setting syntax for elderly rejuvenation. Beehive ecosystem level inspired how to create a sustainable ecosystem that can lead elderly rejuvenation by using space syntax that suitable with elderly behaviour setting.
\end{abstract}

Keywords-Aging Productively, Beehive, Behavior Setting, SOHO, Space Syntax.

\section{INTRODUCTION}

$\mathrm{T}$ HE increasing amount in human life expectancy affect the increasing amount of elderly every year. Aging as one of the phases of human life cycle makes every year there was an additional number of elderly. According to Republic of Indonesia Law Number 13 about Elderly Welfare, Elderly is someone who has reached the age of 60 years old and above. Based on age, there are four types of elderly: Elderly (65 - 70 years old), Young Old ( $70-75$ years old), Old(75 - 80 years old), Very Old(above 80 years old). The increase of quality of life expectancy causes an increase number of elderly people who will be far more than the number of productive age population [1].

The increase amount of age population in Indonesia becomes a serious problem to give a better aging for elderly, not only provide healthcare facilities but also to empower the elderly so they still in the community to maintain their physical and psychological health. By Empowering the elderly, they can live productively and give their contribution to society and to make an interaction between elderly and younger generation. The elderly can share experiences and information to his fellow elderly and younger generation [2]. To respond the issues explained above, the design research aims to upgrade architecture design that can trigger elderly movement to force them to be productive in their aging phase by creating relationship between elderly and natural environment.

According to Figure 1 the proposed design activity program for productive elderly is to make a healthy environment where

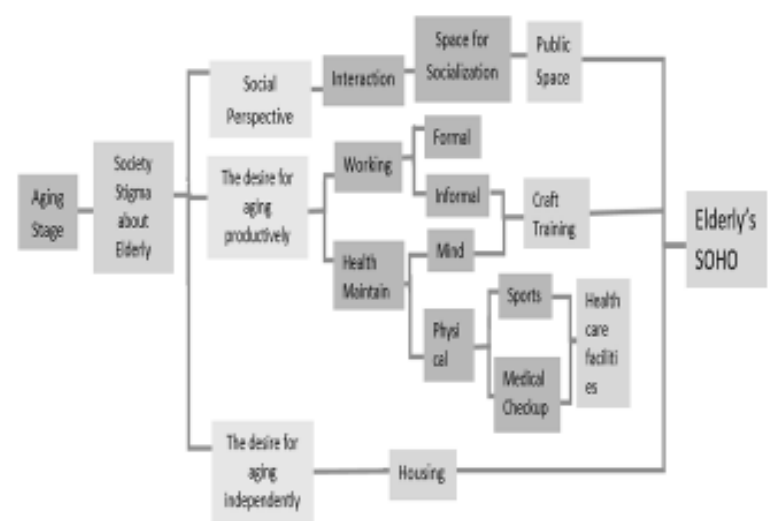

Figure 1. Proposed Design Activity Program Diagram, Source: Author's data, 2018.

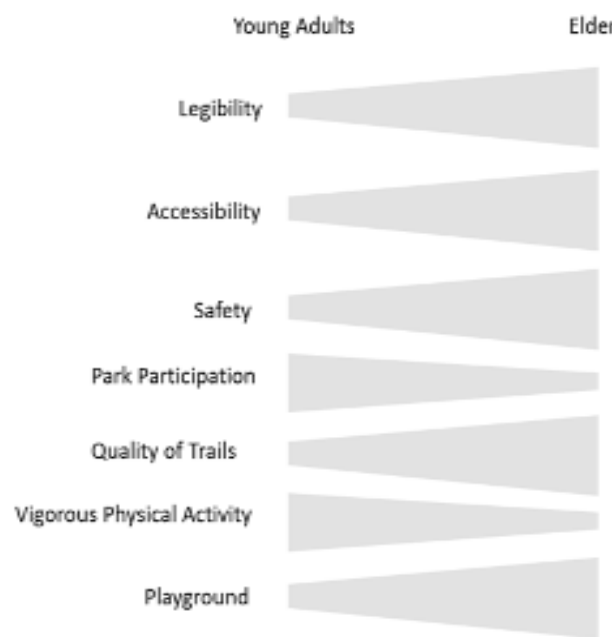

Figure 2. Elderly Need in Open Public Space. Source: Yung, 2016

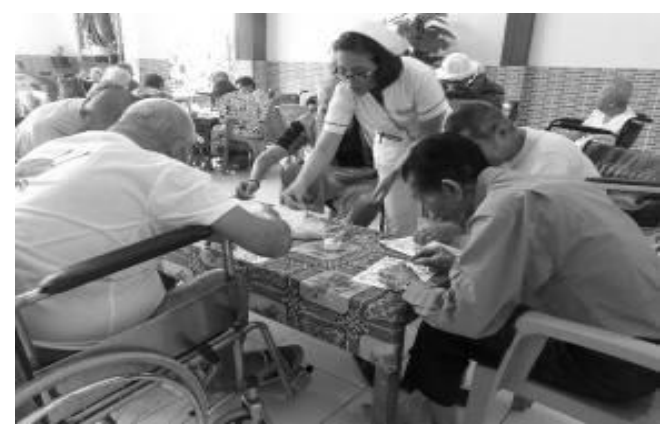

Figure 3. Griya Usia Lanjut St. Yosef Atmosphere (Field Study, 2017).

elderly for a healthy aging in a community that can empowered them. 


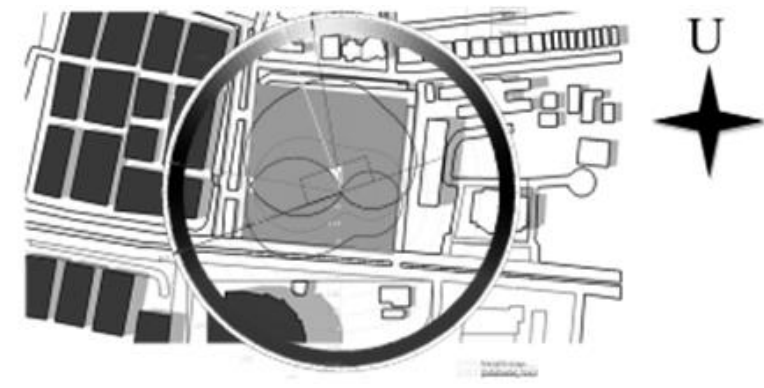

Figure 4. Diagramatic Site Environment Analysis (Ecotect, 2018).

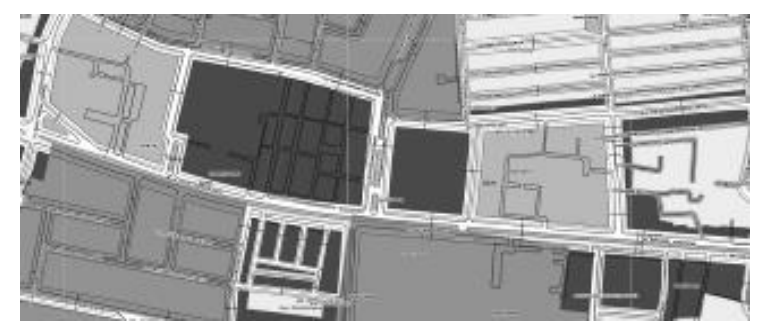

Figure 5. Land Use of Proposed Site (Peta Peruntukan Surabaya, 2016).

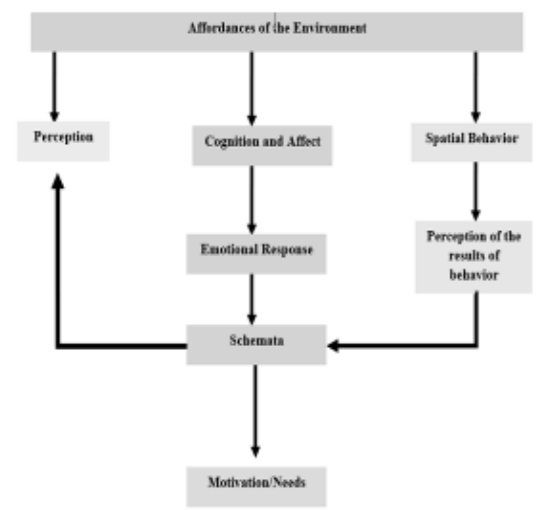

Figure 6. The Fundamental Process of Human Behavior (Lang, 2010).

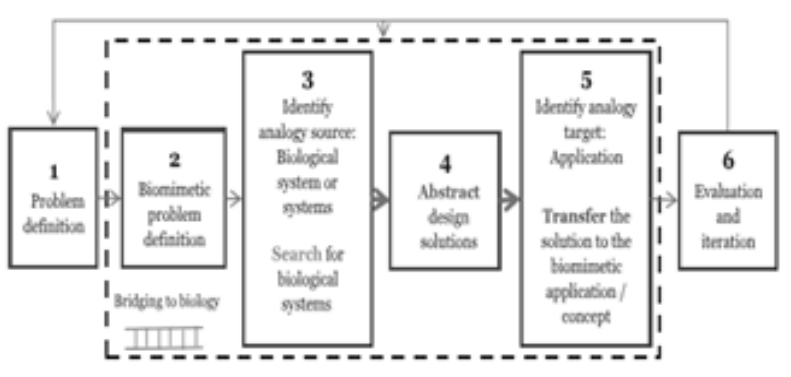

Figure 7. Biomimetic Transfer from Problem to Architecture Design (Cohen, 2016).

The architectural object that can facilitate elderly needs nowadays only nursing home and elderly park. Elderly nursing home has a lack of facilities that can fulfil elderly desire for aging productively. Elderly nursing home nowadays just like a day care to take care the elderly without considering elderly participation to keep productive. Elderly in nursing home just follow the activities from the nursing home. From the interview result based on Appendix 1 and Appendix 2 the atmosphere of elderly housing nowadays only looks like a day care for elderly. Elderly is looked as the object and they need to be taken care by the staff of elderly housing. They don't give elderly a chance to work again to keep their mind healthy.

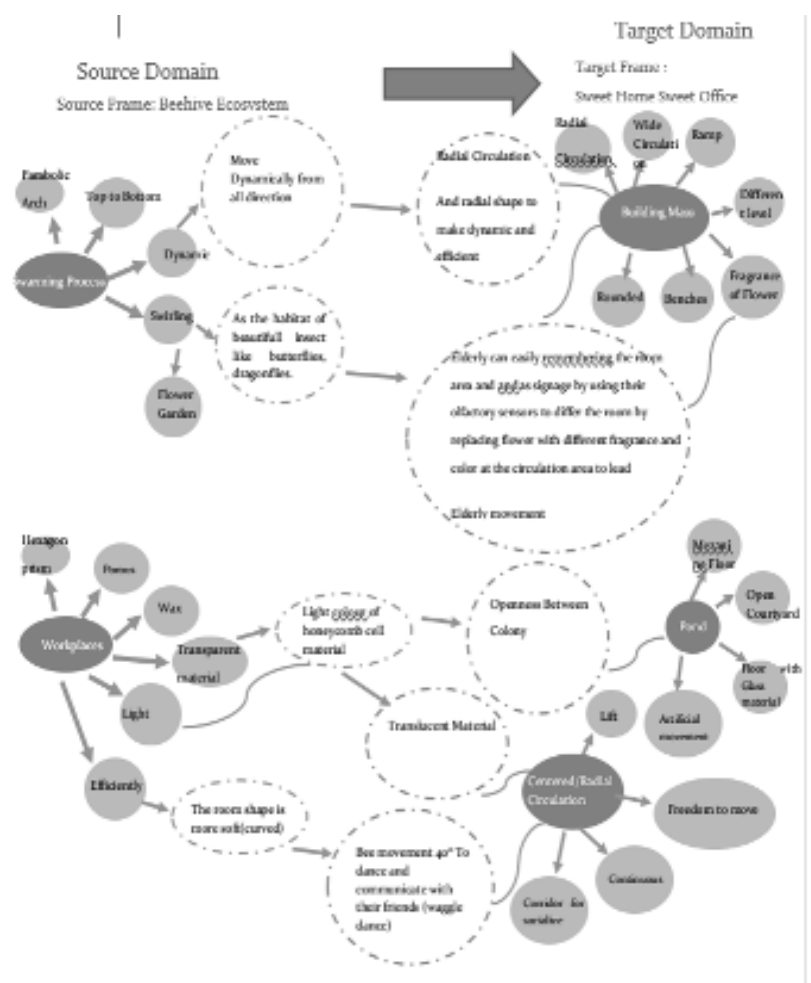

Figure 8. Domain to Domain Transfer System

Table 1.

Elderly Comfort Level

\begin{tabular}{llllllll}
\hline \hline Aspect & Scale (low to high) & & & & \\
Temperature & -3 & -2 & -1 & 0 & 1 & 2 & 3 \\
\hline Humidity & & & & & & & \\
Air Flow & & & & & & & \\
Daylight & & & & & & & \\
Noise Level & & & & & & & \\
\hline \hline
\end{tabular}

Source: Field Study, 2017

Table 2.

Design Criteria

\begin{tabular}{|c|c|c|c|c|c|}
\hline SCOPE & & CONCEPT & $\mathrm{P}$ & C\&A & $\mathrm{S}$ \\
\hline \multirow[t]{12}{*}{ Building } & \multirow[t]{4}{*}{$\begin{array}{l}\text { Formal and } \\
\text { Spatial }\end{array}$} & $\begin{array}{l}\text { Easily recognizable } \\
\text { visual patterns and } \\
\text { relationship }\end{array}$ & o & o & o \\
\hline & & Open Courtyard & & o & $\mathrm{o}$ \\
\hline & & Natural environment & $\circ$ & o & \\
\hline & & Spirit of Place & & & $\circ$ \\
\hline & \multirow{3}{*}{$\begin{array}{l}\text { Room } \\
\text { Comfort }\end{array}$} & Physical Comfort & o & $\circ$ & \\
\hline & & $\begin{array}{l}\text { Psychological } \\
\text { Comfort }\end{array}$ & o & $\circ$ & o \\
\hline & & Social Interaction & & o & o \\
\hline & \multirow[t]{5}{*}{ Accessibility } & $\begin{array}{l}\text { Wide Corridor for } \\
\text { Circulation }\end{array}$ & & $\circ$ & \\
\hline & & Territory Hierarchy & & 0 & \\
\hline & & Barrier Free & & $\circ$ & \\
\hline & & Movement efficiency & & $\circ$ & \\
\hline & & Signage & & $\circ$ & \\
\hline \multirow[t]{4}{*}{ Site } & \multirow{2}{*}{$\begin{array}{ll}\text { Formal and } \\
\text { Spatial }\end{array}$} & Sense of Place & $\mathrm{o}$ & $\mathrm{o}$ & $\mathrm{O}$ \\
\hline & & Natural Environment & $\mathrm{o}$ & & $\mathrm{o}$ \\
\hline & \multirow[t]{2}{*}{ Accessibility } & $\begin{array}{l}\text { Ramp as Pedestrian } \\
\text { Pathway }\end{array}$ & & o & o \\
\hline & & Open Public Space & $\mathrm{o}$ & $\mathrm{o}$ & $\mathrm{o}$ \\
\hline
\end{tabular}

Source: Author's data, 2018

The Object name is Sweet Home Sweet Office and the building typology is SOHO. Sweet Home Sweet Office is SOHO building form for Elderly. Sweet Home Sweet Office 


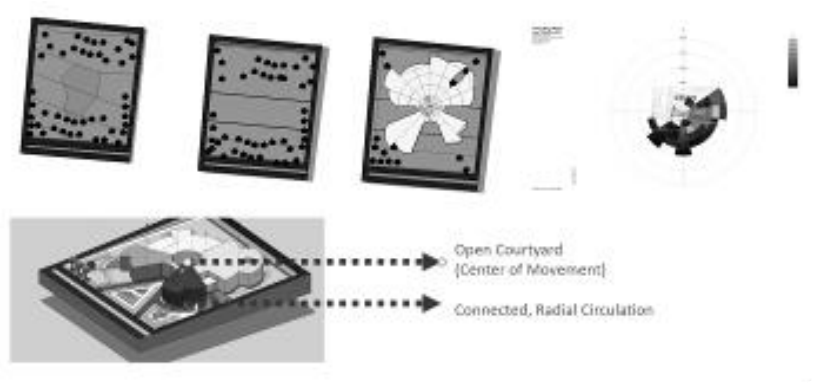

Figure 9. Building Mass Programming (author's data, 2018).

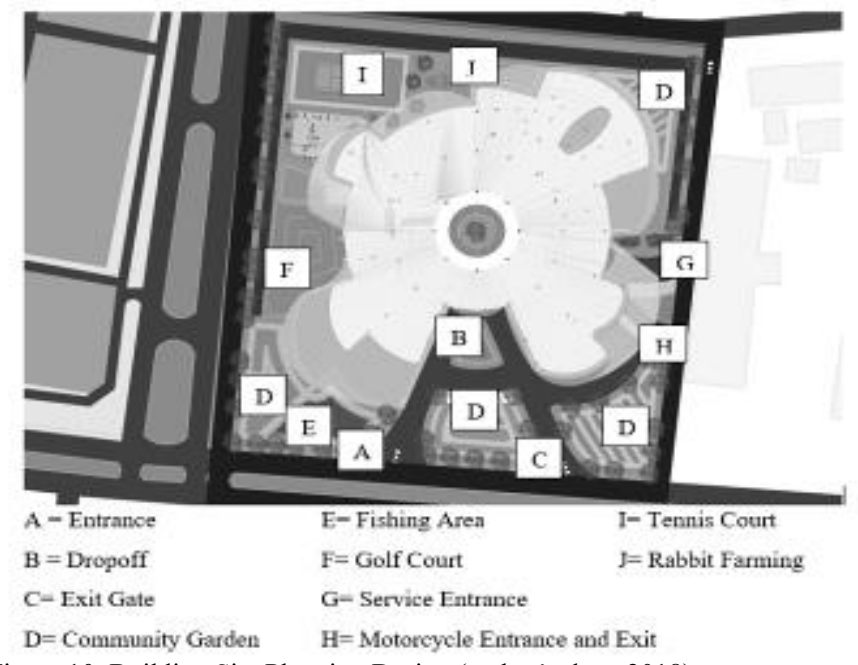

Figure 10. Building Site Planning Design (author's data, 2018).

main goal as the media for Elderly Rejuvenation. Particularly, the functions of this object are:

- As a place to empower elderly through skills traininand creativity such as handicraft, music, fine arts, sports, drama, and massage skills for active elderly and disabled elderly

- As a tool of intergeneration where the elderly and the community can exchange ideas, culture, and interact with each other

- As a public space for elderly fort enjoying their free time, so they can relax and recreate

But the SOHO concept leads to a sense of laziness and the desire to delay work until the interruption and interruption of family members, so SOHO design is needed that can encourage the elderly to remain productive work and also provide privacy, sense of security, comfort and quiet at home. Sweet Home Sweet Office not only provides home and office but also provides medical and entertainment facilities to keep elderly's body and mind healthy and productive.

From figure 4 we can see that the building site best orientation is facing the south side (artery street). By facing the south side we can avoid solar radiation to create thermal comfort for the proposed building.

According to Figure 5 the research site is located in Mayjen Sungkono street in front of Ciputra World land use of this site as Commercial and trading services to make elderly feel they are still a part of the city and they don't feel isolated so they can be triggered to socialize with society and keep productive.

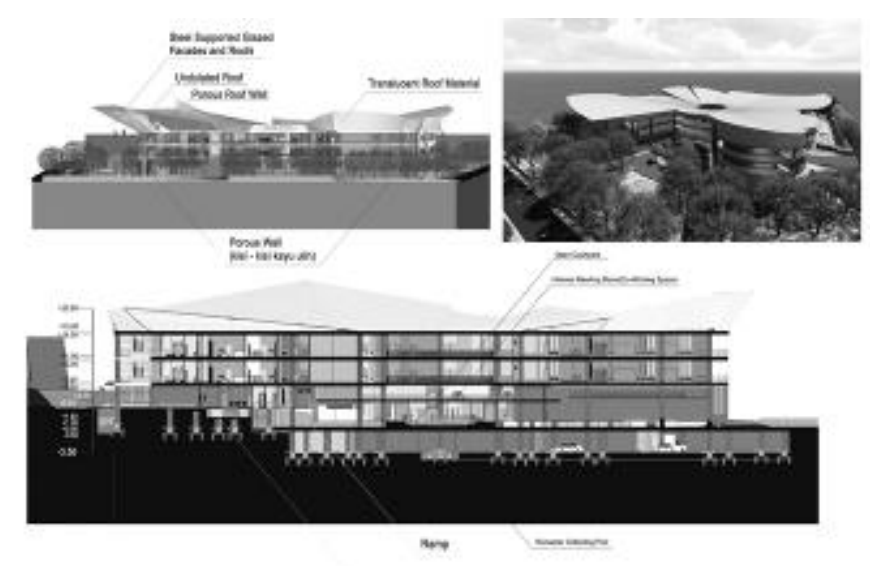

Figure 11. Building Proposed Design (author's data, 2018).

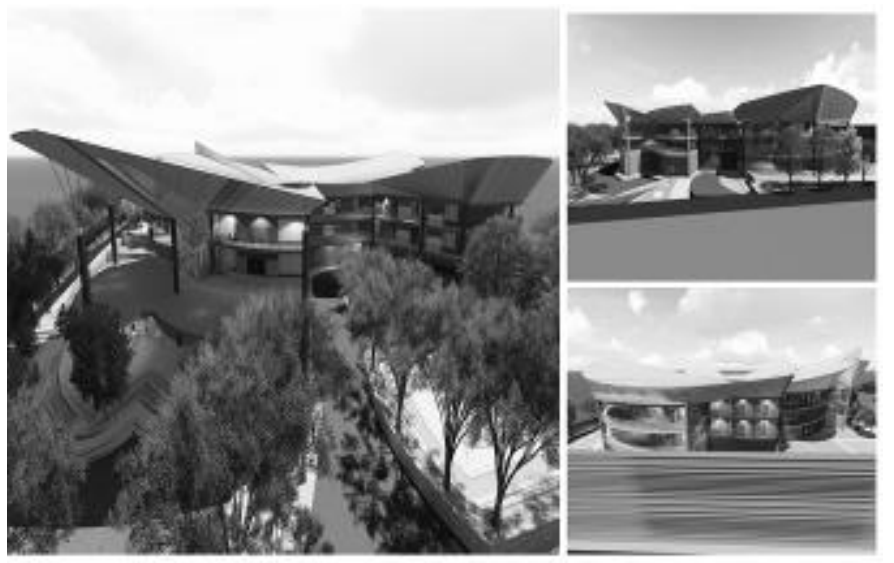

Figure 12. Building Exterior Design (author's data, 2018).

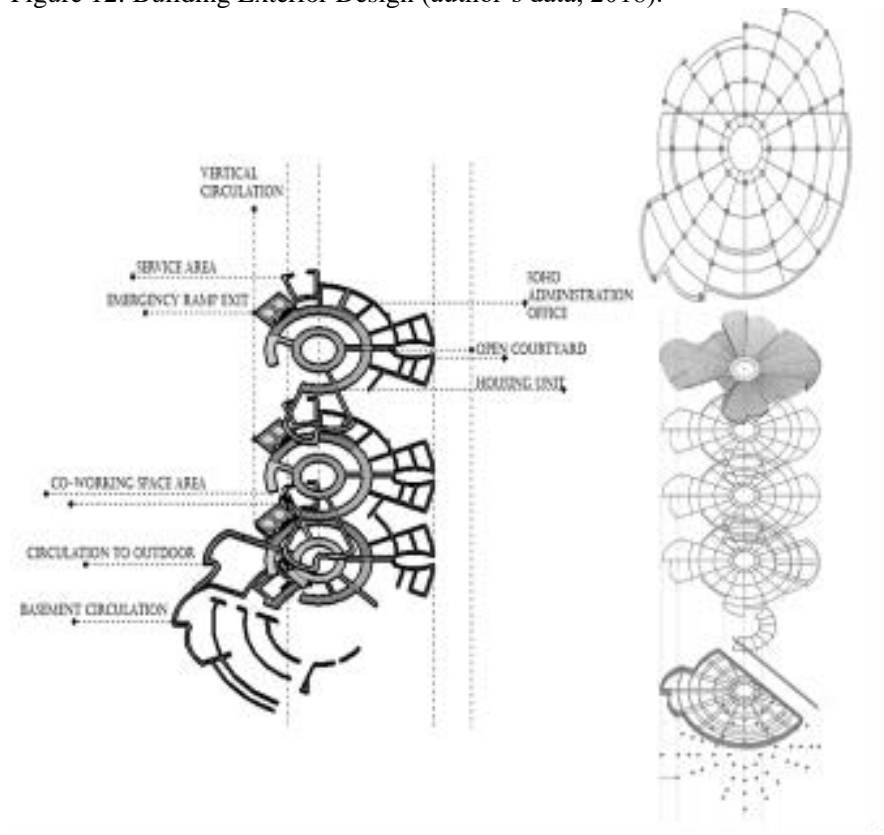

Figure 13. Building Proposed Structure Design (author's data, 2018).

\section{II.DESIGN METHODS}

The process of making this design is Biomimetic which is also known as Biomimicry is one of design method where biology or nature inspired design [3]. Successful biomimetic mimic from nature process that apply into building technology. 


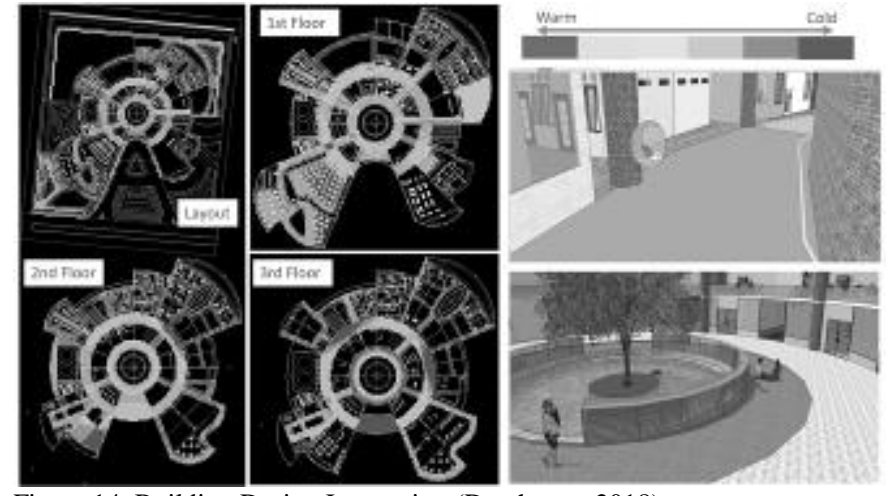

Figure 14. Building Design Integration (Depthmap, 2018).
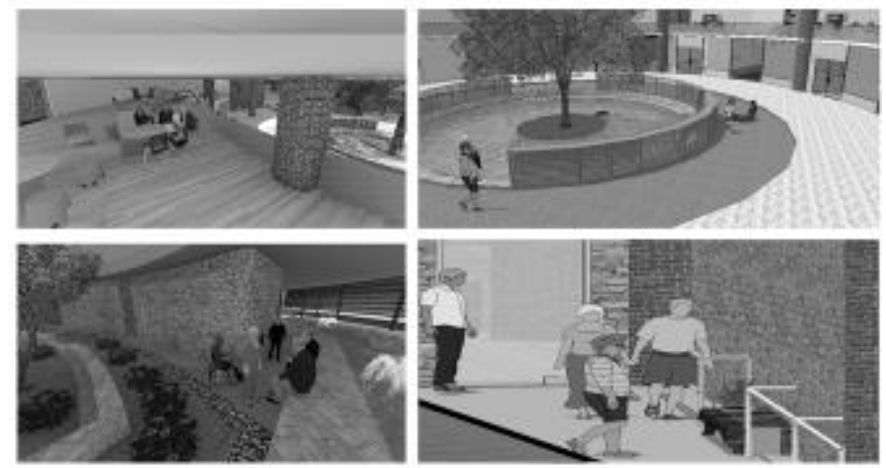

Figure 15. Building Circulation Design (author's data, 2018).

Nature process that inspired this project mimetic from beehive ecosystem level based on elderly need to trigger their movement and create a productive atmosphere for elderly to work. Beehive is chosen because of its function as a sustain model of home and workplace. By combining domain to domain transfer biomimetic is used to create productive behavior for elderly.

Biomimetic is used as a design method to approach elderly behavior setting. The goal for this design is to change elderly behavior for healthy aging. In order to create a setting of behavior we need to arise user motivations.

Analogical transfer system of design knowledge from beehive ecosystem level (nature) to architecture proposed design (technology). The stage of biomimetics design process from a Problem to Biology. According to Figure 7 the first step is defining elderly needs and design problem, after defining elderly needs the second step is looking to the ways how bee colony maintains their hive to stay sustain for their living activity, how they create a workplace that can make they move and work efficiently with less energy. Biomimetic analogical transfer system to resolve my design problem I used structure mapping as domain transfer through analogy and metaphor transfer. Domain to Domain transfer is being used to find design concept. From Figure 8 based on domain to domain transfer we get "Beehiveour" as the main concept of the proposed design. The main concepts that can solve proposed design problem are: Dynamic, Efficient, Transparent, Colorful, and Togetherness.

Building dynamic shape is needed to create dynamic movement for elderly therefore they can be triggered to move. To make a dynamic movement the circulation type that being used is radial circulation. Radial circulation make elderly more easier to move from one room to another room but in another side radial circulation form is also to force elderly to explore the room. Elderly have a limited physical ability to walk.

In order to make elderly easier to walk according to figure 13 elderly circulation pathway using railing to help elderly walk and in circulation area is provided with bench so if elderly get tired while walking they can stop for a while to take a rest and socialize with another elderly.

DEPTHMAP is used to perform a complete analysis of the different space syntax parameters. The different variables estimated through the DEPTHMAP software include the connectivity measure, which is the number of elements that are connected to a certain element, the integration measure which is the distance of an element to all other elements in relation to the number of elements in the complete system and the choice measure which indicates how often an element is passed, when calculating the shortest paths between elements.

Space Syntax is being used for proposed object interior to predict the building warmness and coldness for users of the building. The first step to do is to separate spaces that are public and Private based on the depth (depth) of space and the relationship of space with other space (connectivity). After that the building rooms are programming based on the typology of the building to determine the nature of the space by space syntax.

One of the process to answer the questions in problem formulation is managed by research method, which is equal to the objectives of this research. The research method that is used to reach the goal is qualitative method which is based on strategy, paradigm, and model implementation. The qualitative method is being used to gain the environment comfort parameter for the elderly, the activities that elderly needs, elderly behavior, the facts of proposed building site.

Beside of qualitative method, this research also need quantitative method to formulate the gained data from qualitative method becomes simple statistic range of data.

In order to achieve the objective on this research is going to use qualitative and quantitative method. Mixed methods are being used for this research study to create an environment that suitable with elderly comfort and to change their behavior setting.

According to Table 1 based on field study is held at Griya Usia Lanjut St. Yosef Surabaya and the participants for this research are productive elderly (independent elderly) shows that the participants feel comfortable with the environment of Griya Usia Lanjut St. Yosef Surabaya.

\section{CONCEPTS AND FINAL DESIGN}

Behavior setting is going to play a major role in the approaching process in this design research. Six principles are implemented to the design: Perception $(\mathrm{P})$, Cognition and Affect, Spatial Behavior(S). All are analyzed by using Depthmap software.

Site form is terrain land to create a comfort pedestrian pathway to trigger elderly to explore outdoor activity the site is reorganized with cut and fill system to make it is easier for elderly to walk around. For mass programming the building 
following the trees position and the wind direction to locate inlet and outlet. Utilization of natural elements.

The building macro organization on the site is based on the building function it will be grouped by the function of each facilities. The elderly housing will be located at the backside of the side to make peace atmosphere for elderly to relax. Meanwhile for public facilities such as entertaining facilities and healthcare facilities will be located at the front side of the site. The circulation is radial circulation to give free access for the user to explore the building atmosphere and choose their own path to enjoy the building atmosphere and to socialize.

Architecture object has 4 area that become one mass like beehive mass programming where every area is unite becomes one (mixed used). The dynamic shape analogy from bee swarming activity and the function of the dynamic shape is to facilitate wind break and to maximize air movement inside the building to create thermal comfort for elderly. The roof shape is undulated roof, parabolic arc and at the center as open courtyard is flat roof to collect rain water.

According to figure 4 building site is located in low terrain level area. Therefore it is possible for proposed building design to use passive cooling strategy. In line with Samodra (2017) vertical ventilation is one of passive cooling strategy that suitable with urban density by considering its environment noise level [4]. For the building corridor using porous wall to let air and light come inside the building and to create an environment that feel more naturally for elderly. Porous wall material is from concrete and using colorful material based on its zoning.

The warmth areas have a high integration level and they are located at circulation, outdoor area(balcony), and at the center of the building (open courtyard). Areas with low integration level have a cold color (turquoise, light blue, and blue). Low integration areas located at private zoning such as changing room, elderly housing, sauna room, and SOHO administration office. From figure 14 the warmth area location at the center of building with the radial shape and elderly tend to gather around at circulation area because they can socialization with everyone that pass the circulation area.

According to figure 13 the building structural systems is rigid space frame structure that mimic from honeycomb that has rigid structure. The roof structural system is undulated roof with parabolic shape from swarming bee analogy, and also to collect wind to move inside it.

From Figure 14 building integrity, and connectivity on radial room configuration is depend on the radial size. At the center radial (open courtyard) has function as shared room to gather people for socializing. At the Figure 14 there is different result because the change of radial size and furniture placing showing that corridor is used as social place.

\section{CONCLUSION}

The proposed building design is to create interaction between elderly and natural environment in order to trigger elderly movement to stay productive both physically and psychologically. In line with Yung [5], this proposed design has capability to show how elderly behavioral responses by analyzing the influence of spatial configuration on spatial behavior and responses of elderly in built environment Syntax parameters to create room configuration that can provide elderly needs to socialize to determine the social interaction of the space.

The proposed design goal must be integrated to gain its design goal. The integration output affects elderly behavior setting from building circulation, aperture, furniture placement, and outdoor natural environment. Depthmap is being used to analyze building space integrity and connectivity to achieve the performance requirement goal for this research. By using Depthmap for elderly SOHO space syntax from elderly SOHO floor plan the result is elderly tend to gather at circulation area. space/area with high integrity is located at the centre of building (open courtyard), space with radial shape has a role as collecting space/ assembly point where elderly tend to socialize. Then space integrity and connectivity can be split into different sections according to its collecting radial size.

\section{REFERENCES}

[1] WHO, "Global Health and Aging," 2011.

[2] Wijayanti and et al, "Places where the elderly meet friends at Banyumanik Public Housing, Semarang, Indonesia Spaces of the elderly based on the living arrangement (case study: Banyumanik Public Housing)," J. Soc. Behav. Sci., vol. 50, pp. 405-417, 2012.

[3] Y. H. Cohen and Y. Reich, Biomimetic Design Method for Innovation and Sustainability. Switzerland: Springer International Publishing, 2016.

[4] F. Samodra and T. Badai, "Analysis of Resilient Design by Thermoacoustic Adaptation of Tropical Urban Model," J. Archit. Urban., vol. 41, no. 4, pp. 305-315, 2017.

[5] Yung and et al, "Social needs of the elderly and active aging in public open spaces in urban renewal," J. Cities, vol. 52, pp. 114122, 2016. 